\title{
Studies on Constitution of Vitreous Silicate by Infrared Absorption Spectra
}

\author{
By Tsutomu Yanagase* and Yukio Suginohara*
}

\begin{abstract}
The infrared absorption studies have been carried out on the silicate glasses as an approach to clarify the constitution of molten silicate. As seen in the figures of infrared absorption spectra obtained for the binary silicates of $\mathrm{PbO}-\mathrm{SiO}_{2}, \mathrm{CaO}_{-} \mathrm{SiO}_{2}$, $\mathrm{BaO}-\mathrm{SiO}_{2}, \mathrm{ZnO}-\mathrm{SiO}_{2}$ and $\mathrm{Na}_{2} \mathrm{O}-\mathrm{SiO}_{2}$ systems, each vitreous silicate gives characteristic spectral curves. From the result of investigation on the absorption band of $\nu_{3}$ vibration due to $\mathrm{Si}-\mathrm{O}$ stretching mode, it may be predicted that the different kinds of silicate anion can co-exist in vitreous or molten silicates over a certain $\mathrm{SiO}_{2}$ content.
\end{abstract}

(Received April 27, 1970)

\section{Introduction}

The constitution of molten silicate or slags has been investigated by measuring the structure sensitive properties such as density, viscosity, surface tension or electrical conductivity. Since it is considered that the structure of silicate or slag melts is preserved in vitreous silicate at room temperature, the results obtained for molten silicate can be applied to the studies on silicate glasses and those obtained in vitreous silicate by $\mathrm{X}$-ray analysis or the infrared absorption technique will be applicable to the field of liquid silicate. As for a model of silicate glasses, Mackenzie ${ }^{(1)}$ summarized the various pictures so far presented and established his own view based on discrete anion theory.

The infrared absorption spectra of silicate crystal or glass has been measured and demonstrated as one of the direct methods for obtaining a structural picture. Saksena ${ }^{(2)}$ carried out extensive work on infrared absorption spectra of various types of silicate minerals and compared those experimental results with calculated values. Miller et al. ${ }^{(3)}$ and McDevitt et al. (4) summarized the infrared absorption studies on inorganic compounds. Simon et al. ${ }^{(5)}$, Florinskaya et al. ${ }^{(6)}$, Cherneva et al. ${ }^{(7)}$ and Tarte ${ }^{(8)}$ presented the papers concerning glassy or crystalline silicates. Although more data should be needed in order to assign each absorption band to the vibrational mode and in silicate glasses and other amorphous or noncrystalline substances, only broad absorption bands are observed on infrared spectral curves due to the spread of force constant of the bonds in glass lattice, the measurements of a shift of absorption band due to the changing of $\mathrm{SiO}_{2}$ content or the comparison of the bands with those of other silicates will be of great importance for a structural approach to the silicate melts or glasses. As seen in binary phase diagrams of metal oxide and silica, it is obvious that the effect of metal

* Department of Metallurgy, Kyushu University, Fukuoka, Japan.

(1) J.D. Mackenzie : Modern Aspects of the Vitreous Slate, p. 3, 204.

(2) B. D. Saksena : Trans. Farad. Soc ; 57(part 2) (1961), 242.

(3) F.A. Miller and C.H.Wilkins : Anal. Chem., 24 (1952), 1253.

(4) N.t. McDevitt and W. L. Baum : Spectrochem. Acta, 20 (1964), 799.

Trans. J IM oxide on silicate anion will be quite different even though the same amount of metal oxide is introduced. For instance, in the $\mathrm{PbO}-\mathrm{SiO}_{2}$ system, there exist one continuous liquid phase and three stable compounds. On the other hand, in the $\mathrm{ZnO}-\mathrm{SiO}_{2}$ system, two wide liquid ranges appear on the $\mathrm{SiO}_{2}$ side and its stable compound is only one as $2 \mathrm{ZnO} \cdot \mathrm{SiO}_{2}$. It can be said, therefore, that the characteristic silicate model of each metal oxidesilica system should be presented rather than a generalized picture. In this paper, the vitreous samples in $\mathrm{PbO}$ $\mathrm{SiO}_{2}, \mathrm{ZnO}-\mathrm{SiO}_{2}, \mathrm{BaO}-\mathrm{SiO}_{2}, \mathrm{Na}_{2} \mathrm{O}-\mathrm{SiO}_{2}$ and $\mathrm{CaO}-\mathrm{SiO}_{2}$ systems were chosen for infrared absorption studies.

\section{Experimental Procedure}

The $\mathrm{SiO}_{2}$ used was pure quartz (rock crystal) powder and other metal oxides were analytical grade reagenis. $\mathrm{Na}_{2} \mathrm{O}$ and $\mathrm{CaO}$ were introduced as carbonates. Metallic oxide and silica were mixed and melted in a $\mathrm{Pt}$ crucible (below $1600^{\circ} \mathrm{C}$ ) or a $\mathrm{Pt}$ crucible containing $30 \% \mathrm{Rh}$ (above $1600^{\circ} \mathrm{C}$ ). The vitreous samples were obtained by rapid cooling from a temperature above the melting point of the silicates after keeping for $I \sim 3 \mathrm{hr}$ and stirring in a complete molten state. In the case of $\mathrm{PbO}-\mathrm{SiO}_{2}$ and $\mathrm{ZnO}-\mathrm{SiO}_{2}$ systems molten silicate can be poured into water, while $\mathrm{CaO}-\mathrm{SiO}_{2}, \mathrm{Na}_{2} \mathrm{O}-\mathrm{SiO}_{2}$ and $\mathrm{BaO}-\mathrm{SiO}_{2}$ systems, which react with water, are cooled with water from outside of the crucible. About $100 \mathrm{mg}$ of the samples which are apt to crystallize while cooling are weighed and subjected to quenching into mercury after melting in the $\mathrm{Pt}$ envelope containing $30 \% \mathrm{Rh}$. The samples obtained are ground to the diameter of less than $2 \mu$ with an alumina mortar. For the $\mathrm{Na}_{2} \mathrm{O}-\mathrm{SiO}_{2}$ system, grinding and mixing should be carried out in benzine or argon gas atmosphere in order to prevent from reacting with $\mathrm{H}_{2} \mathrm{O}$ or $\mathrm{CO}_{2}$. About $0.5 \sim$ $1.5 \mathrm{mg}$ of the vitreous samples were mixed with $200 \mathrm{mg}$ of $\mathrm{KBr}$ powder in alumina mortar and pressed into a

(5) I. Simon and H. O. McMahon : J. Amer. Cer. Soc., 36 (1953), 160.

(6) V. A. Florinskaya and R. S. Pechenkina : J. Structural Chemistry, $4(1963), 783$.

(7) É. F. Cherneva and V.A. Florinskaya : J. Structural Chemistry, $5(1964), 655$.

(8) P. Tarte: Bull. Soc. Fran. Ceram., 58 (1963), 13 ; Spectrochim. Acta, 18 (1962), 467.

1970 Vol.11 
pellet under $10 \mathrm{t} / \mathrm{cm}^{2}$ in vacuum. The infrared absorption spectra were obtained with the Shimadzu IR-600 or IR-27 G spectro-photometer equipped with grating, covering the range of $1700 \sim 400 \mathrm{~cm}^{-1}$.

\section{Experimental Results}

\section{1. $\mathrm{Na}_{2} \mathrm{O}-\mathrm{SiO}_{2}$ system}

The spectral curves obtained in the $\mathrm{Na}_{2} \mathrm{O}-\mathrm{SiO}_{2}$ system are shown in Fig. 1. The strong absorption band in the $1100 \sim 900 \mathrm{~cm}^{-1}$ region is ascribed to $\mathrm{Si}-\mathrm{O}$ stretching vibrations $\left(\nu_{3}\right)$. The absorption bands around $800 \mathrm{~cm}^{-1}$ and $470 \mathrm{~cm}^{-1}$ are assigned as stretching mode $\left(\nu_{1}\right)$ and $\mathrm{Si}-\mathrm{O}-\mathrm{Si}$ bending mode $\left(\nu_{4}\right)$ respectively. In this paper, the change of absorption band due to stretching vibration $\left(\nu_{3}\right)$ with metal oxide contents will mainly be discussed. In vitreous silica the absorption peak of $\nu_{3}$ vibration, which is observed at about $1110 \mathrm{~cm}^{-1}$, tends to shift to a lower frequency, $1065 \mathrm{~cm}^{-1}$ at $80 \% \mathrm{SiO}_{2}{ }^{*}$, as $\mathrm{Na}_{2} \mathrm{O}$ is added, due to a decrease of the number of bridging oxygen in silicate anion. Further addition of $\mathrm{Na}_{2} \mathrm{O}$ resulted in the appearance of a new absorption peak, which continuously shifts to $930 \mathrm{~cm}^{-1}$ for $60 \% \mathrm{SiO}_{2}$ with increasing $\mathrm{Na}_{2} \mathrm{O}$ content. Beyond this composition, as seen in Fig. 1, the absorption band of $1065 \mathrm{~cm}^{-1}$ again shifts toward a lower wave number, finally about $990 \mathrm{~cm}^{-1}$ for $40 \% \mathrm{SiO}_{2}$, as $\mathrm{Na}_{2} \mathrm{O}$ is increased.

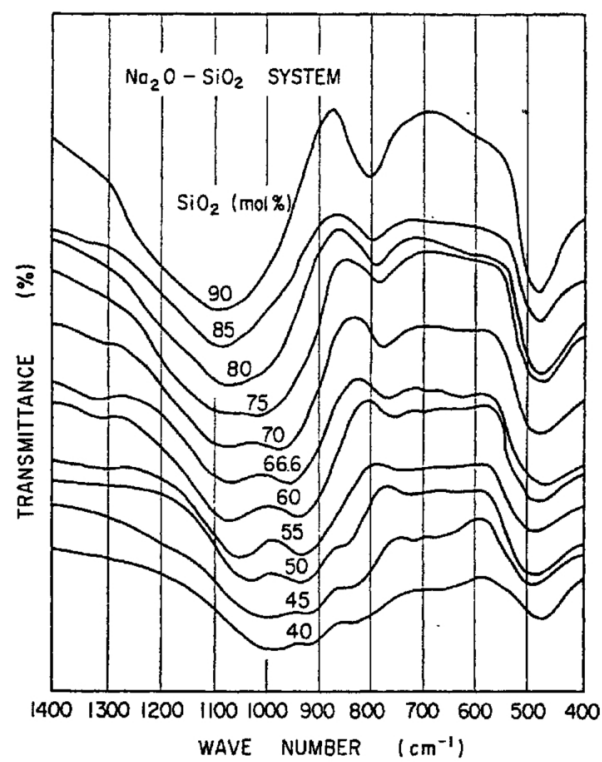

Fig. 1 Infrared absorption spectra of sodium silicate glasses.

\section{2. $\mathrm{CaO}-\mathrm{SiO}_{2}$ system}

The absorption spectra in this system are shown in Fig. 2. The absorption peak at $1110 \mathrm{~cm}^{-1}$ observed in pure vitreous silica shifts to $1100 \mathrm{~cm}^{-1}$ by $10 \%$ addition of $\mathrm{CaO}$, which remains unchanged until $65 \% \mathrm{SiO}_{2} . \quad \mathrm{On}$ the other hand, another peak around $930 \mathrm{~cm}^{-1}$ appears for $72 \% \mathrm{SiO}_{2}$ and remains until $55 \% \mathrm{SiO}_{2}$, getting intenser as the $\mathrm{CaO}$ content is increased. Between them one more absorption band exists, that is, about $1065 \mathrm{~cm}^{-1}$

* $\mathrm{SiO}_{2}$ content in binary silicate is expressed in mole\% unless otherwise mentioned. at $70 \% \mathrm{SiO}_{2}, 1030 \mathrm{~cm}^{-1}$ at $60 \sim 55 \% \mathrm{SiO}_{2}$, and 1010 $\mathrm{cm}^{-1}$ at $50 \% \mathrm{SiO}_{2}$. The absorption band of $965 \mathrm{~cm}^{-1}$ is observed at the compositions of $45 \sim 40 \% \mathrm{SiO}_{2}$. The samples containing $35 \% \mathrm{SiO}_{2}$ seemed to partly crystallize during cooling, showing characteristic sharp absorption bands in the curve.

\section{BaO-SiO 2 system}

As seen in Fig. 3, the absorption maxima of $\nu_{3}$ stretching vibration shifts toward the lower wave number

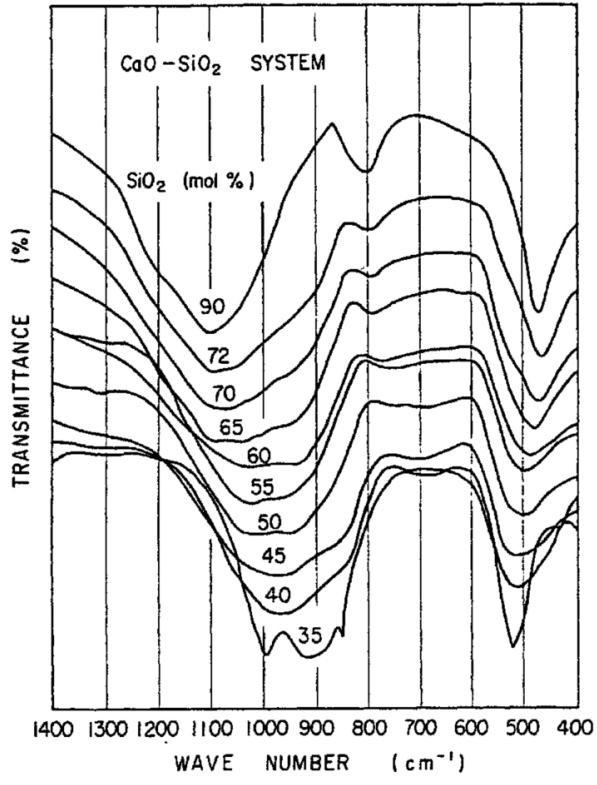

Fig. 2 Infrared absorption spectra of calcium silicate glasses.

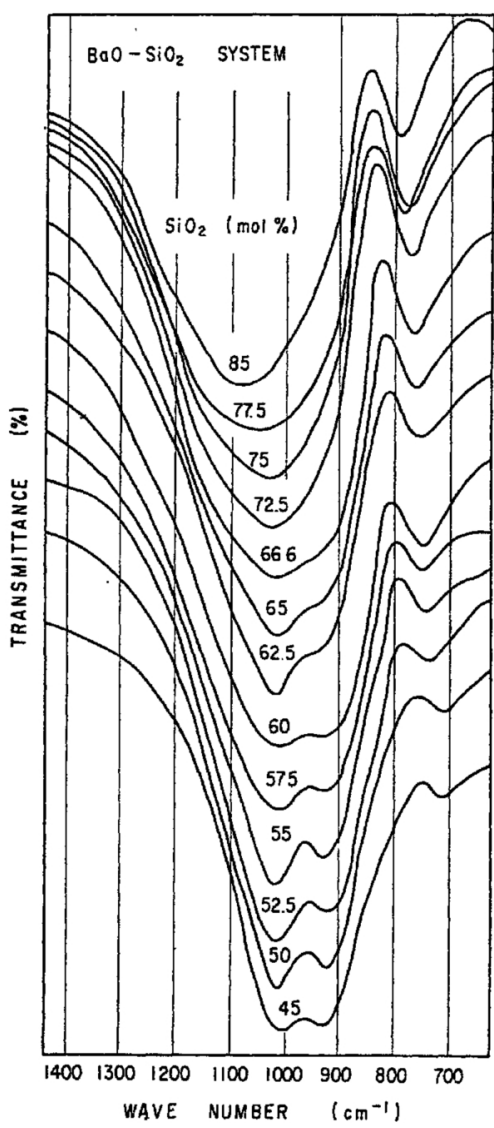

Fig. 3 Infrared absorption spectra of barium silicate glasses. 
side, i.e., from $1110 \mathrm{~cm}^{-1}$ in pure $\mathrm{SiO}_{2}$ to $1020 \mathrm{~cm}^{-1}$ for $70 \% \mathrm{SiO}_{2}$ as the amount of $\mathrm{BaO}$ is increased. Then new absorption peak in the $920 \sim 930 \mathrm{~cm}^{-1}$ region appears and becomes intenser with increasing $\mathrm{BaO}$, while the absorption peak of $1020 \mathrm{~cm}^{-1}$ still remains. For the silicates containing less than $45 \% \mathrm{SiO}_{2}$, however, the absorption peak of $1020 \mathrm{~cm}^{-1}$ seemed to shift to a lower wave number.

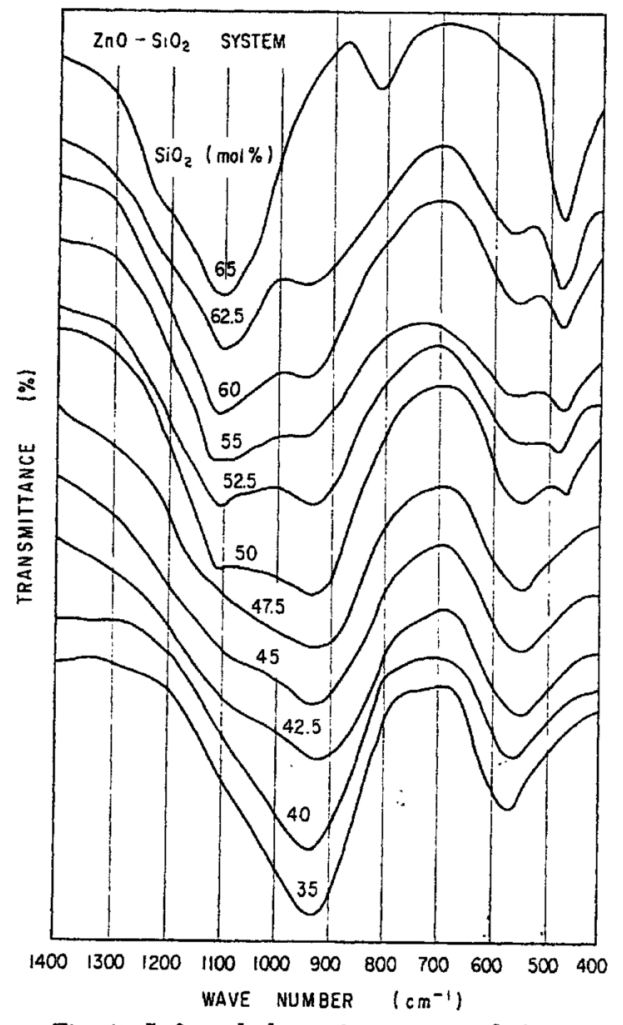

Fig. 4 Infrared absorption spectra of zinc silicate glasses.

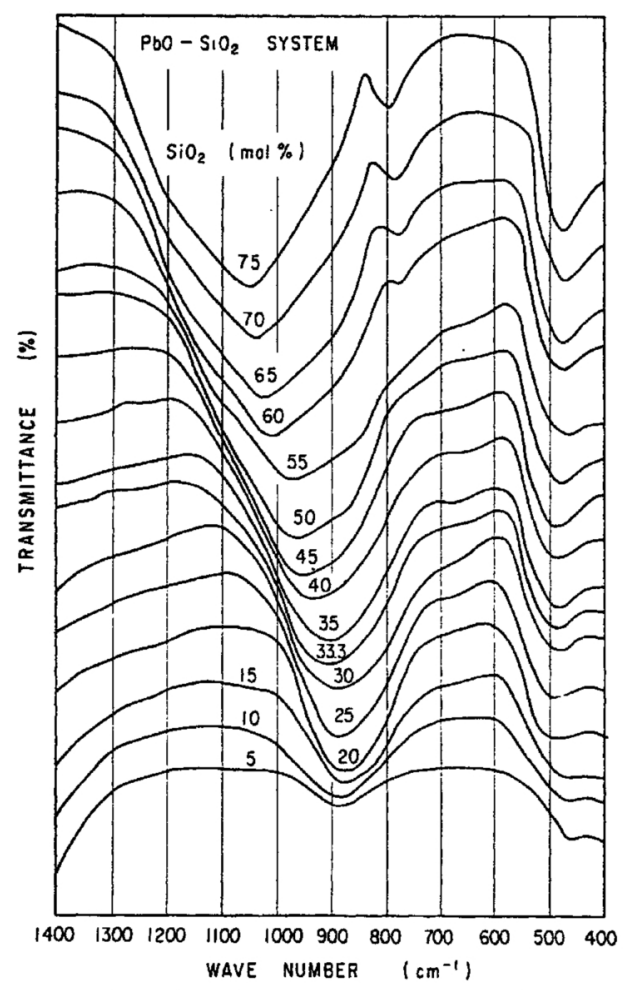

Fig. 5 Infrared absorption spectra of lead silicate glasses.

\section{4. $\mathrm{ZnO}_{-} \mathrm{SiO}_{2}$}

The results on this system are shown in Fig. 4, The characteristic figure in this system is that no continuous shift of the absorption bands was observed over the whole experimental range. On the addition of $\mathrm{ZnO}$ to silica, it should be noted that the intensity in absorption of 1110 $\mathrm{cm}^{-1}$ becomes weaker and another band at $930 \mathrm{~cm}^{-1}$ becomes stronger. In the regions with less band than $40 \% \mathrm{SiO}_{2}$, absorption band of $1110 \mathrm{~cm}^{-1}$ disappeared and only the band of $930 \mathrm{~cm}^{-1}$ remains.

\section{5. $\mathrm{PbO}-\mathrm{SiO}_{2}$ system}

The spectral curves obtained for the $\mathrm{PbO}-\mathrm{SiO}_{2}$ system are shown in Fig. 5. The absorption maxima due to $\mathrm{Si}-\mathrm{O}$ stretching vibration shift continuously to a lower wave number, $890 \mathrm{~cm}^{-1}$ at $30 \% \mathrm{SiO}_{2}$, as the melt becomes richer in $\mathrm{PbO}$, and then the absorption peak remains constant even with further addition of $\mathrm{PbO}$.

\section{Discussion}

Summarized spectral data of vitreous samples in the above-mentioned binary silicates are shown in Fig. 6 . In the $\mathrm{PbO}-\mathrm{SiO}_{2}$ system, as seen clearly in this figure, the wave number of the absorption peak decreases almost linearly with increasing $\mathrm{PbO}$ content in the silicate. In the $\mathrm{ZnO}-\mathrm{SiO}_{2}$ system, the immiscibility in the liquid phase is observed on the silica rich side, i.e., more than about $65 \% \mathrm{SiO}_{2}$. The absorption spectra of the samples on the silica side are similar to pure vitreous silica, and those on the $\mathrm{ZnO}$ side are similar to that of $60 \% \mathrm{SiO}_{2}$. The spectral data are quite contrary to those of the $\mathrm{PbO}$ $\mathrm{SiO}_{2}$ system and only two absorption bands are observed. The $\mathrm{BaO}-\mathrm{SiO}_{2}$ system exhibits a S-shaped solidification curve on the phase diagram. As $\mathrm{BaO}$ is added to silica, the absorption band at first continuously shifts to a lower wave number until at $65 \% \mathrm{SiO}_{2}$, and then splits into

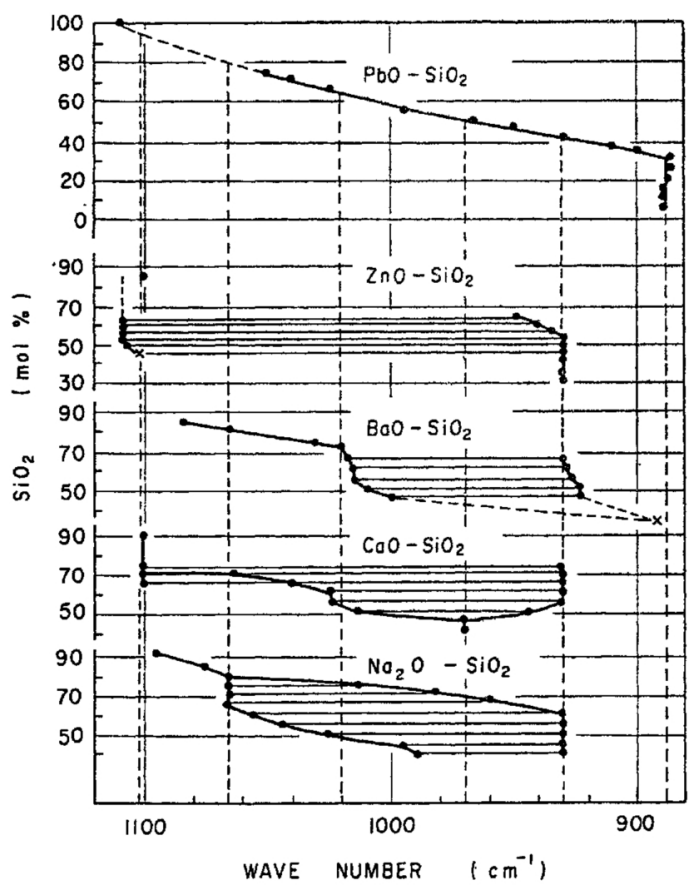

Fig. 6 Relation between wave number of absorption peak $\left(\nu_{3}\right)$ and $\mathrm{SiO}_{2}$ content in binary silicate glasses. 
two peaks which remain almost unchanged even with further addition of $\mathrm{BaO}$. The $\mathrm{CaO}-\mathrm{SiO}_{2}$ system shows liquid immiscibility for more than about $70 \% \mathrm{SiO}_{2}$. The absorption bands around $1100 \mathrm{~cm}^{-1}$ and $930 \mathrm{~cm}^{-1}$ are observed as in the $\mathrm{ZnO}-\mathrm{SiO}_{2}$ system. In addition, one more absorption band is seen, shifting with the change in composition. In the $\mathrm{Na}_{2} \mathrm{O}-\mathrm{SiO}_{2}$ system, as mentioned before, the absorption band at first gradually shifts up to $1065 \mathrm{~cm}^{-1}$ with the addition of $\mathrm{Na}_{2} \mathrm{O}$ and splits into two peaks.

If the wave number of the absorption bands in Fig. 6 which stay constant independent of the change in composition are taken into account, six kinds of absorption bands are observed on the curves. If it is assumed that such absorption peaks are attributed to the difference of silicate anions in each silicate, the following six silicate anions will be considered as constituents.

\section{Absorption peak around $900 \mathrm{~cm}^{-1}$}

Saksena pointed out that the absorption band due to the $\nu_{3}$ vibration of $\mathrm{SiO}_{4}^{4-}$ is located at $893 \mathrm{~cm}^{-1}$. In the $\mathrm{PbO}-\mathrm{SiO}_{2}$ system, as seen from the results obtained, one strong absorption peak due to the $\nu_{3}$ vibration of silicate anion was shown on the spectral curves over the whole experimental range. The silicates containing less than $33.3 \% \mathrm{SiO}_{2}$ may be considered to have $\mathrm{SiO}_{4}^{4-}$ (as silicate anion) and the absorption peaks for the composition are located around $900 \sim 890 \mathrm{~cm}^{-1}$. This absorption peak, therefore, may be assigned to the $\nu_{3}$ vibration of $\mathrm{SiO}_{4}^{4-}$.

\section{Absorption peak around $930 \mathrm{~cm}^{-1}$}

In the $\mathrm{PbO}-\mathrm{SiO}_{2}$ system, the composition having this absorption peak corresponds to $40 \% \mathrm{SiO}_{2}$, i.e., $\mathrm{Si}_{2} \mathrm{O}_{7}^{6-}$ as silicate anion. During crystallization of vitreous lead silicate containing $40 \% \mathrm{SiO}_{2}$, it was found that the unstable compound $\mathrm{Pb}_{3}\left(\mathrm{Si}_{2} \mathrm{O}_{7}\right)$ once formed and then dissociated into $\mathrm{PbSiO}_{3}$ and $\mathrm{Pb}_{2} \mathrm{SiO}_{4}$ for further heat treatment ${ }^{(9)}$. In the $\mathrm{ZnO}_{\mathrm{n}} \mathrm{SiO}_{2}$ system, there exists no compound like $3 \mathrm{ZnO} \cdot 2 \mathrm{SiO}_{2}$ on the equilibrium phase diagram. On crystallization of glassy zinc silicate, however, the unstable compound whose structure is just the same as de-hydrated crystal of calamine $\left[\mathrm{Zn}_{4}\left(\mathrm{Si}_{2} \mathrm{O}_{7}\right)(\mathrm{OH})_{2} \cdot 2 \mathrm{H}_{2} \mathrm{O}\right]$ on the $\mathrm{X}$-ray pattern is formed before changing into stable $\mathrm{Zn}_{2} \mathrm{SiO}_{4}$. Consequently, in the silicate melt or glass, there may be silicate anion $\mathrm{Si}_{2} \mathrm{O}_{7}^{6-}$ which will be assigned to $930 \mathrm{~cm}^{-1}$ as the absorption band.

\section{Absorption peak around $970 \mathrm{~cm}^{-1}$}

Since the absorption band of $\mathrm{PbO}-\mathrm{SiO}_{2}\left(50 \% \mathrm{SiO}_{2}\right)$ corresponds to $970 \mathrm{~cm}^{-1}$ as shown in the $\mathrm{PbO}-\mathrm{SiO}_{2}$ system, this peak may be assigned to $\mathrm{Si}_{n} \mathrm{O}_{3^{n}}^{2 n-}(n \geqq 3)$ as a ring structure of silicate anion.

(9) H. Ito and T. Yanagase : Trans. JIM, 1 (1960), 115.

\section{Absorption peak around $1020 \mathrm{~cm}^{-1}$}

In the $\mathrm{PbO}-\mathrm{SiO}_{2}$ system, the absorption peak of the composition having $66 \% \mathrm{SiO}_{2}$ appears at $1020 \mathrm{~cm}^{-1}$, which is also found in the absorption of $\mathrm{BaSi}_{2} \mathrm{O}_{5}$ in the $\mathrm{BaO}-\mathrm{SiO}_{2}$ system. Hence this peak will be attributed to the $\nu_{3}$ vibration in the $\mathrm{Si}_{2 n} \mathrm{O}_{5^{n}}^{2 n-}(n \geqq 3)$ layer structure or discrete anion.

\section{Absorption peak around $1065 \mathrm{~cm}^{-1}$}

This absorption peak corresponds to that of the compound $\mathrm{MO} \cdot 4 \mathrm{SiO}_{2}$ in $\mathrm{BaO}-\mathrm{SiO}_{2}, \mathrm{Na}_{2} \mathrm{O}-\mathrm{SiO}_{2}$ systems. Silicate anion will be shown as three dimensional complex ions like $\mathrm{Si}_{12} \mathrm{O}_{27}^{6-}$ or $\mathrm{Si}_{16} \mathrm{O}_{36}^{8-}$.

\section{Absorption peak around $1100 \mathrm{~cm}^{-1}$}

This peak is attributed to the $\nu_{3}$ vibration of vitreous silica. As a result of the above consideration, it may be said that two or three different kinds of silicate anions could co-exist in such silicate melts as $\mathrm{ZnO}-\mathrm{SiO}_{2}, \mathrm{BaO}-$ $\mathrm{SiO}_{2}, \mathrm{CaO}-\mathrm{SiO}_{2}$ and $\mathrm{Na}_{2} \mathrm{O}-\mathrm{SiO}_{2}$ systems. In the $\mathrm{PbO}-$ $\mathrm{SiO}_{2}$ system, the silicate network will continuously break down into smaller structural units as $\mathrm{PbO}$ is added to $\mathrm{SiO}_{2}$, and the resulting infrared absorption band also shifts continuously from a higher wave number to the lower one. Since no change in silicate anion will be expected for the silicates containing less than $33 \% \mathrm{SiO}_{2}$, the absorption band will remain constant. In the $\mathrm{ZnO}$ $\mathrm{SiO}_{2}$ system, the addition of $\mathrm{ZnO}$ to the silica network causes a rupture of $\mathrm{Si}-\mathrm{O}$ bonds and results in the formation: of $\mathrm{Si}_{2} \mathrm{O}_{7}^{6-}$ type ion. None of other type of silicate anion will exist in the silicate melts for the compositional range examined. Since zinc silicates less than $30 \% \mathrm{SiO}_{2}$ were impossible to obtain in a glassy state, it is not clear if they have other types of ion like $\mathrm{SiO}_{4}^{4-}$. When $\mathrm{BaO}$ is added to $\mathrm{SiO}_{2}$, the silicate network gradually breaks down as seen in the $\mathrm{PbO}-\mathrm{SiO}_{2}$ system. At $66 \% \mathrm{SiO}_{2}$ the $\mathrm{Si}_{2 n} \mathrm{O}_{5 n}^{2 n-}$ type ion becomes stable and then $\mathrm{Si}_{2} \mathrm{O}_{7}^{6-}$ ion tends to appear. With further addition of $\mathrm{BaO}$, the absorption band due to the former becomes weaker and that due to the latter becomes stronger. In the $\mathrm{CaO}_{-} \mathrm{SiO}_{2}$ system, the silicate rich in $\mathrm{CaO}$ for two liquids range shows the existence of $\mathrm{Si}_{2} \mathrm{O}_{7}^{6-}$ ion as well as vitreous silica as seen in the $\mathrm{ZnO}-\mathrm{SiO}_{2}$ system. Vitreous silica will dissociate into $\mathrm{Si}_{2 n} \mathrm{O}_{5 n}^{2 n-}$ type ion between $72 \sim 60 \% \mathrm{SiO}_{2}$, and $\mathrm{Si}_{2} \mathrm{O}_{7}^{6-}$ and $\mathrm{Si}_{2 n} \mathrm{O}_{5 n}^{2 n-}$ type ion may be stable in the range of $60 \sim 50 \% \mathrm{SiO}_{2}$. Below $50 \% \mathrm{SiO}_{2}$ the $\mathrm{Si}_{n} \mathrm{O}_{3 n}^{2 n-}$ ring type ion may be stable. Addition of $\mathrm{Na}_{2} \mathrm{O}$ to $\mathrm{SiO}_{2}$ will result in a gradual break-down of the threedimensional network up to $80 \% \mathrm{SiO}_{2}$, and then the three-dimensional complex ion like $\mathrm{Si}_{12} \mathrm{O}_{27}^{6-}$ or $\mathrm{Si}_{16} \mathrm{O}_{36}^{8-}$ may be stable in the range of $80 \sim 65 \% \mathrm{SiO}_{2}$, and at the same time, other ion will continue to dissociate into smaller ion group until $\mathrm{Si}_{2} \mathrm{O}_{7}^{6-}$ ion appears at $60 \% \mathrm{SiO}_{2}$. The three-dimensional complex ion like $\mathrm{Si}_{12} \mathrm{O}_{27}^{6-}$ or $\mathrm{Si}_{16} \mathrm{O}_{36}^{8-}$ starts to change into smaller ion at about $60 \% \mathrm{SiO}_{2}$. 